\title{
Preface
}

\section{PET/MR Imaging: Clinical Applications}

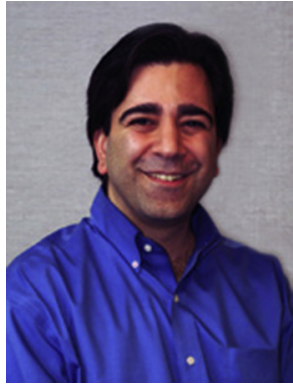

Drew A. Torigian, MD, MA, FSAR

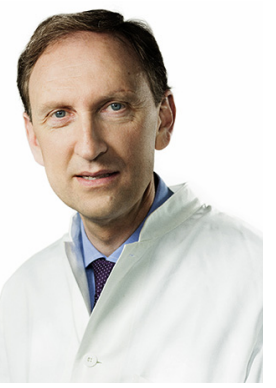

Andreas Kjær, MD, PhD, DMSC

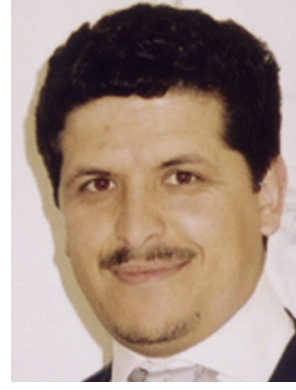

Habib Zaidi, PhD, PD

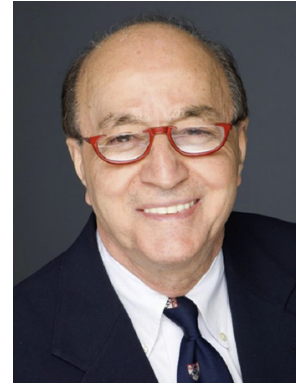

Abass Alavi, MD, MD (Hon), PhD (Hon), DSc (Hon)

Editors

Clinical PET/MRI systems have recently become commercially available, offering many advantages compared with PET/CT, leading to much enthusiasm in the medical community at large. Such advantages include a reduced exposure to ionizing radiation, superior soft tissue contrast resolution, and the capability to provide functional and multiparametric imaging data based on advanced MRI techniques (eg, diffusion-weighted imaging, dynamic perfusion imaging, magnetic resonance spectroscopy, or magnetic resonance elastography) that are complementary with the molecular data provided by PET. However, the higher costs, the slower scanning times with associated lower patient throughputs, the increased complexity, and the relative lack of diagnostic benefit of PET/MRI in some clinical applications relative to either PET/CT or independently acquired PET and MRI have somewhat dampened this initial excitement. Yet, it is likely that PET/MRI will still play an important future role in the clinical diagnostic imaging assessment of certain groups of patients with certain disease conditions, although such niche applications are still being defined. Additional technical challenges hampering quantitative imaging including the lack of consensus on reliable and accurate MRI-guided attenuation correction techniques are being addressed by active research groups in the scientific literature.

Therefore, in this issue of PET Clinics, we have enclosed a series of review articles that focus on clinical PET/MRI. In particular, clinical applications of PET/MRI for the evaluation of malignancy (including lymphoma, head and neck cancer, breast cancer, lung cancer, gastrointestinal tract cancers, and gynecologic cancers), brain disease, musculoskeletal disorders, and cardiovascular disease are discussed. We also briefly provide an article regarding our future perspectives on clinical $\mathrm{PET} / \mathrm{MRI}$ in the oncologic setting. This issue nicely complements the April 2016 issue, "PET/MRI: Advances in Instrumentation and Quantitative Procedures," (Vol. 11, No. 2) edited by Dr Habib Zaidi.

We would like to thank all of the authors who contributed these articles, and we hope that the readers of these articles will learn much and apply what is learned to the future clinical practice of PET/MRI for the benefit of their patients.

$$
\begin{array}{r}
\text { Drew A. Torigian, MD, MA, FSAR } \\
\text { Department of Radiology } \\
\text { Hospital of the University of Pennsylvania } \\
3400 \text { Spruce Street } \\
\text { Philadelphia, PA 19104, USA } \\
\text { Andreas Kjær, MD, PhD, DMSc } \\
\text { Department of Clinical Physiology } \\
\text { Nuclear Medicine \& PET } \\
\text { and Cluster for Molecular Imaging } \\
\text { Rigshospitalet and } \\
\text { University of Copenhagen } \\
\text { KF-4012, Blegdamsvej } 9 \\
2100 \text { Copenhagen, Denmark } \\
\text { Habib Zaidi, PhD, PD }
\end{array}
$$
Division of Nuclear Medicine \& Molecular Imaging Geneva University Hospital $\mathrm{CH}-1211$ Geneva, Switzerland 
Abass Alavi, MD, MD (Hon), PhD (Hon), DSc (Hon) Department of Radiology Hospital of the University of Pennsylvania 3400 Spruce Street Philadelphia, PA 19104, USA
E-mail addresses: Drew.Torigian@uphs.upenn.edu (D.A.Torigian) akjaer@sund.ku.dk (A. Kjær) habib.zaidi@hcuge.ch (H. Zaidi) abass.alavi@uphs.upenn.edu (A. Alavi) 